06

\title{
Полевая электронная микроскопия науглероженного рения
}

\author{
() Д.П. Бернацкий, В.Г. Павлов
}

Физико-технический институт им. А.Ф. Иоффре РАН, Санкт-Петербург

E-mail: bernatskii@ms.ioffe.ru

Поступило в Редакцию 15 фревраля 2017 г.

Методами полевой электронной микроскопии исследован рост углеродных структур на поверхности рениевого полевого эмиттера. Образование графена происходит на плотноупакованных гранях кристалла рения и приводит к снижению работы выхода. Для образования графеновых островков на рении требуется значительно большее время экспозиции в парах бензола, чем на иридии. Нагрев науглероженного рениевого полевого эмиттера до температур, близких к температуре плавления, с последующим снижением температуры не приводит к изменению работы выхода и полевого электронного изображения. Выявленные особенности объясняются высокой растворимостью углерода в рении.

DOI: $10.21883 /$ PJTF.2017.12.44715.16748

Различные углеродные структуры на поверхности полевых эмиттеров представляют интерес для исследований эмиссионных свойств поверхности, повышения стабильности и эффективности эмиттера [1-4]. Поэтому изучение роста различных форм углерода на поверхности металлических полевых эмиттеров представляет важную задачу, поскольку открывается возможность совместить достоинства изготовления металлических эмиттеров с уникальными свойствами эмиттеров из углеродных материалов $[1,3]$.

В данной работе с помощью полевых эмиссионных методов изучаются углеродные структуры, которые могут образовываться при пиролизе паров бензола на рениевом полевом эмиттере. Хорошо известно, что при термическом разложении органических молекул в частности бензола, на плоской поверхности многих каталитически активных металлов образуется монослойная графитовая пленка (графен) или двумерные островки графена [5]. Графеновая пленка изолирует поверхность металлической подложки, и разложение углеводородов прекращается 
после образования монослоя графена. При пиролизе паров бензола на близкой к полусферической форме поверхности иридиевого полевого эмиттера графен, как было обнаружено, образуется на низкоиндексных плоских гранях кристалла иридия, оказывая существенное влияние на эмиссионные свойства эмиттера [6-8].

Полевой эмиттер для исследований изготавливался из рениевой проволоки путем электрохимического травления в кислотном растворе. Затем производили отжиг при температуре $T=2500 \mathrm{~K}$ в высоком вакууме $\left(P<10^{-9}\right.$ Torr $)$. Во время отжига происходили очистка рения и формирование кристаллической структуры эмиттера в виде острия с радиусом вершины порядка $500 \mathrm{~nm}$. Процессы очистки и формирования острия формы отжига контролировались по полевым электронным изображениям поверхности в эмиссионном микроскопе. Науглероживание рения осуществлялось по методике, изложенной в $[5,6]$. Для этого производили выдержку эмиттера в парах бензола при давлении $5 \cdot 10^{-5}$ Torr и температуре эмиттера $T=1700 \mathrm{~K}$. Согласно этой методике, вначале происходит растворение углерода в объеме рения с последующим образованием графена на поверхности и понижением работы выхода. Характеристики Фаулера-Нордгейма, измеренные до и после экспозиции эмиттера в парах бензола, позволяли вычислить работу выхода поверхности до и после экспозиции, определить фактор электрического поля и напряженность электрического поля при полевой электронной эмиссии.

Исследования проводились в полевом эмиссионном микроскопе [9]. Для визуализации полевых электронных и ионных изображений поверхности эмиттера в нанометровом масштабе использовалась схема регистрации, состоящая из двух микроканальных пластин диаметром $56 \mathrm{~mm}$ и люминесцентного экрана. Вращение эмиттера в горизонтальной плоскости позволяло расширить область регистрации.

После формирования полевого эмиттера в режиме полевой электронной микроскопии можно было наблюдать стандартное изображение поверхности кристалла рения с центральной гранью (112̄0) [10]. Помимо центральной грани в область регистрации детектора попали две грани типа (1100), две грани типа (1122) и четыре грани типа (1110). На перечисленных гранях полевая электронная эмиссия отсутствовала вследствие более высокой работы выхода по сравнению с окружающей поверхностью. После науглероживания эмиттера в парах бензола полевое электронное изображение поверхности эмиттера существенно

Письма в ЖТФ, 2017, том 43, вып. 12 


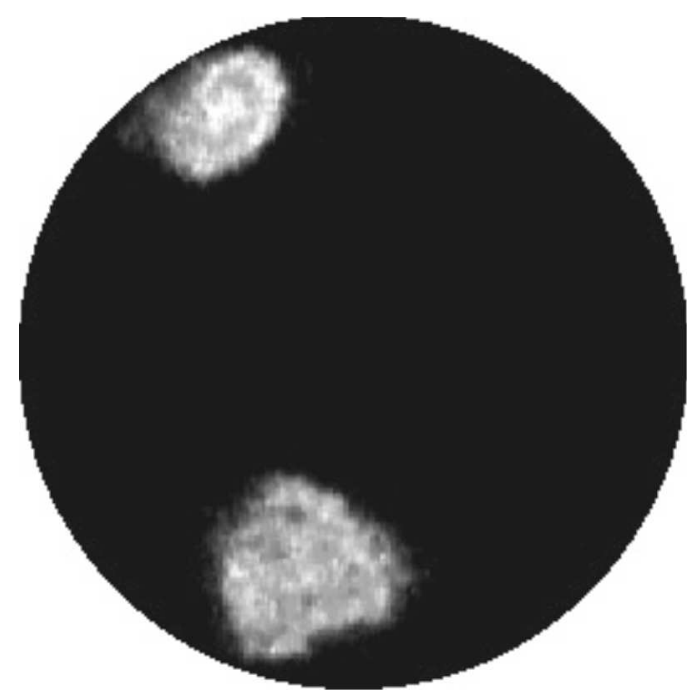

Рис. 1. Полевое электронное изображение науглероженного рениевого эмиттера с двумя гранями типа (1110).

изменилось. Полевая электронная эмиссия была обнаружена только с четырех граней типа (1110). На рис. 1 приведено полевое электронное изображение науглероженного рениевого эмиттера с двумя гранями типа (1110). Две другие грани, которые расположены симметрично справа, не попадают в поле экрана. Но, при небольшом повороте эмиттера в горизонтальной плоскости, их можно наблюдать. Для вычисления работы выхода поверхности и фактора электрического поля использовали формулу Фаулера-Нордгейма для полевой электронной эмиссии в виде [11]

$$
J=1.4 \cdot 10^{-6}\left(E^{2} / \varphi\right) \cdot 10^{4.39 / \sqrt{\varphi}} \cdot 10^{-2.82 \cdot 10^{7}\left(\varphi^{3 / 2} / E\right)},
$$

где $J\left(\mathrm{~A} / \mathrm{cm}^{2}\right)$ - плотность тока, $\varphi(\mathrm{eV})$ - работа выхода, $E=\beta U-$ напряженность электрического поля $(\mathrm{V} / \mathrm{cm}), \beta\left(\mathrm{cm}^{-1}\right)-$ фактор электрического поля, $U(\mathrm{~V})$ - приложенное напряжение. Измеренные вольт-амперные характеристики полевого эмиттера до и после экспозиции в парах бензола в координатах Фаулера-Нордгейма 


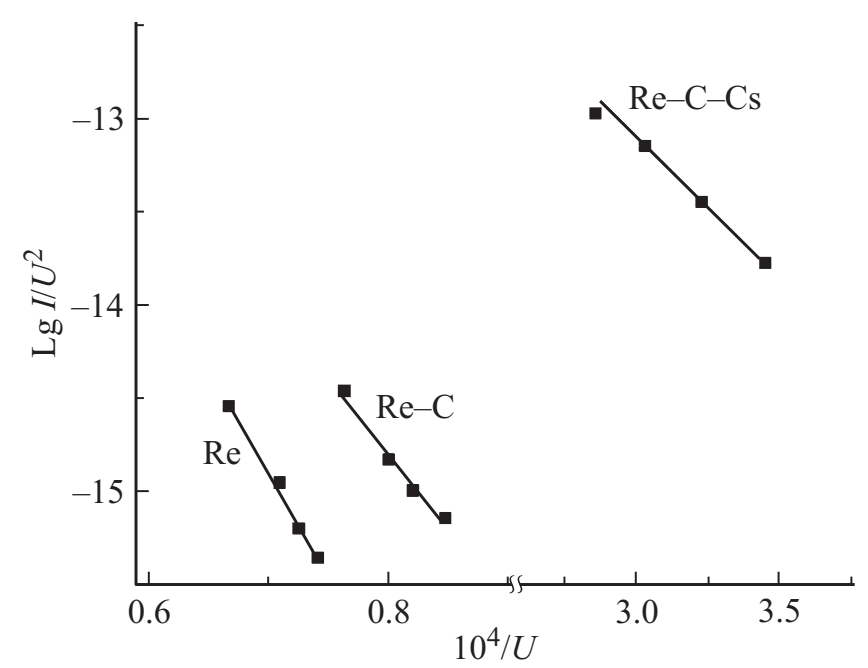

Рис. 2. Вольт-амперные характеристики полевого эмиттера в координатах Фаулера-Нордгейма.

$\operatorname{Lg} I / U^{2}=f(1 / U)$, где $I-$ сила тока полевой электронной эмиссии, приведены на рис. 2. Из характеристик Фаулера-Нордгейма для чистого рениевого эмиттера и рениевого эмиттера с адсорбированными атомами цезия вычислялся фактор усиления электрического поля. При определении фактора электрического поля работа выхода рениевого полевого эмиттера принималась равной $4.9 \mathrm{eV}$. Работа выхода рениевого эмиттера с адсорбированными атомами цезия при оптимальном покрытии $\theta_{\text {opt }}$ (при минимальной работе выхода) определялась из экспериментальной зависимости работы выхода $\varphi$ от покрытия цезием $\theta$ (рис. 3). Атомы цезия наносились равными порциями по времени из прямоканального источника, состоящего из хромата цезия и восстановителя. Зная фактор электрического поля, получили из графика Фаулера-Нордгейма значение работы выхода поверхности науглероженного рения $\varphi=4.2 \mathrm{eV}$. Близкое значение работы выхода было получено в работе [12] при создании графенового покрытия на плоской поверхности текстурированной рениевой ленты с выходом грани (1010).

Экспериментальные характеристики тока полевой эмиссии электронов в координатах Фаулера-Нордгейма, приведенные на рис. 2,

Письма в ЖТФ, 2017, том 43, вып. 12 


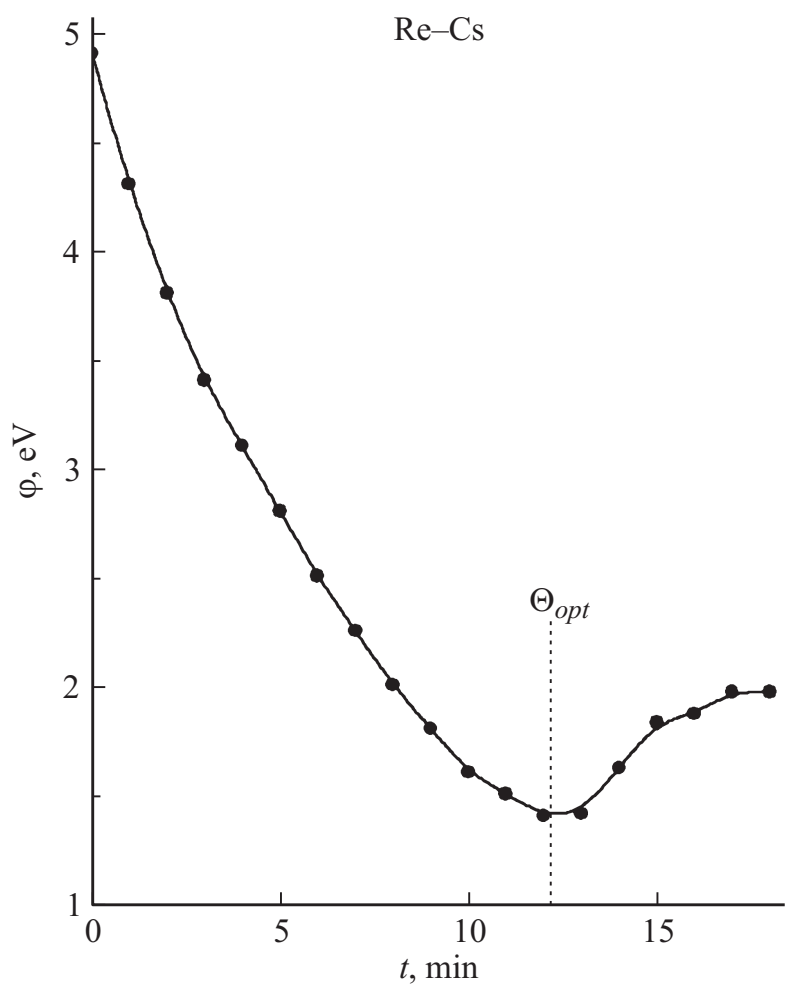

Рис. 3. Зависимость работы выхода рениевого эмиттера от времени напыления атомов цезия.

достаточно хорошо аппроксимируются прямыми линиями. Наблюдается небольшое отклонение в области более сильных полей для системы $\mathrm{Re}-\mathrm{C}-\mathrm{Cs}$ (рис. 2), которое связано с изменением концентрации цезия на вершине эмиттера вследствие поверхностной диффузии атомов цезия в неоднородном электрическом поле.

В работах $[8,13]$ было описано образование углеродных структур на гранях типа (111) иридиевого полевого электронного эмиттера. При этом нагрев иридиевого эмиттера до температуры $T=2300 \mathrm{~K}$ приводил к полному удалению углерода с поверхности. В отличие от системы $\mathrm{Ir}-\mathrm{C}$ в системе $\mathrm{Re}-\mathrm{C}$ было обнаружено сохранение полевого элек- 
тронного изображения и эмиссионных характеристик после отжига при температурах, близких к температуре плавления рения. Это говорит о том, что структура поверхности до и после отжига не изменяется. С другой стороны, трудно предположить, что при таком нагреве углеродное покрытие остается на поверхности. В работе [12] было показано, что при температурах, превышающих температуру науглероживания рения, графен на плоской текстурированной поверхности рения с выходом одной грани типа (1100) разрушается и растворяется в объеме. При охлаждении углерод может выходить на поверхность с образованием графена и хемосорбированного двумерного углеродного газа. В случае криволинейной поверхности полевого эмиттера с выходом разных кристаллографических граней на поверхность скорость растворения и выхода углерода на разных участках, а также механизмы образования углеродных структур поверхности могут быть различными. Это может привести к образованию углеродных структур разного фазового состава: на одних гранях образуются островки графена, а на других участках поверхности - рост графитовой фазы. На рис. 1 видно, что на некоторых участках граней электронная эмиссия немного больше. Это может быть вызвано локальным усилением напряженности электрического поля на трехмерных углеродных образованиях. При отжиге эмиттера углерод с поверхности переходит в объем, при последующем охлаждении наблюдаем обратный выход углерода на поверхность с восстановлением первоначальной ее структуры.

Таким образом, с помощью полевой электронной микроскопии в результате визуализации модификаций полевой электронной эмиссии с поверхности рения при его науглероживании наблюдается переход эмиссии электронов в область граней рения типа (1110). Работа выхода эмиттера при этом понижается вследствие образования графена. Обнаружено восстановление углеродной структуры поверхности после отжига эмиттера при высоких температурах.

\section{Список литературы}

[1] Шешин Е.П. Структура поверхности и автоэмиссионные свойства углеродных материалов. М.: Изд-во МФТИ, 2001. 288 с.

[2] Forbes R.G. // Sol. St. Electron. 2001. V. 45. P. 779-808.

[3] Kumar S., Duesberg G.S., Pratap R., Raghavan S. // Appl. Phys. Lett. 2014. V. 105. P. 103107.

Письма в ЖТФ, 2017, том 43, вып. 12 
[4] Ильичев Э., Кулешов А., Набиев Р. и др. // Электроника. Спецвыпуск (00137). 2014. C. 143-155.

[5] Rut'kov E.V., Gall N.R. // Physics and applications of graphene - experiments / Ed. S. Mikhailov. Publisher: InTech. 2011. P. 209-292.

[6] Бернацкий Д.П., Павлов В.Г. // Письма в ЖТФ. 2013. Т. 39. В. 23. С. 8-12.

[7] Бернацкий Д.П., Павлов В.Г. // Письма в ЖТФ. 2014. Т. 40. В. 23. С. 104 110.

[8] Бернацкий Д.П., Павлов В.Г. // Письма в ЖТФ. 2015. Т. 41. В. 20. С. 44-49.

[9] Бернацкий Д.П., Павлов В.Г. // Известия РАН. Сер. Физ. 2009. Т. 73. С. 713715.

[10] Beach Th., Vanselow R.// Appl. Phys. 1974. V. 4. P. 265-270.

[11] Ненакаливаемые катоды / Под ред. М.И. Елинсона. М.: Сов. радио, 1974. C. 169.

[12] Рутьков Е.В., Галль Н.Р., Потехина Н.Д. // ФТТ. 2014. Т. 56. В. 8. С. 1645 1650.

[13] Берначкий Д.П., Павлов В.Г. // Письма в ЖТФ. 2016. Т. 42. В. 11. С. 105110. 